\title{
Particle fluxes in the ocean: comparison of sediment trap data with results from inverse modeling
}

\author{
R. Usbeck ${ }^{\mathrm{a}, *}$, R. Schlitzer ${ }^{\mathrm{a}}$, G. Fischer ${ }^{\mathrm{b}}$, G. Wefer $^{\mathrm{b}}$ \\ ${ }^{a}$ Alfred Wegener Institute for Polar and Marine Research, PF 120161, 27515 Bremerhaven, Germany \\ ${ }^{\mathrm{b}}$ University of Bremen, PF 330440, 28334 Bremen, Germany
}

Received 15 February 2002; accepted 22 January 2003

\begin{abstract}
Biological production lowers the $\mathrm{CO}_{2}$ concentrations in the surface layer of the ocean, and sinking detritus "pumps" nutrients and $\mathrm{CO}_{2}$ into the deep ocean. Quantifying the efficiency of the biological pump is a prerequisite for global $\mathrm{CO}_{2}$ budgets. Sediment traps are commonly used to directly measure the vertical particle flux; however, for logistical and financial reasons, traps cannot provide area-wide data sets. Moreover, it has been shown that sediment traps can under- or overestimate particle fluxes considerably. In this paper, we present a new technique to estimate the downward flux of particulate matter with an adjoint model. Hydrographic and nutrient data are used to calculate the mean ocean circulation together with parameters for particle fluxes using the AWI Adjoint Model for Oceanic Carbon Cycling (AAMOCC). The model is fitted to the property concentrations by systematically varying circulation, air-sea fluxes, export production and remineralization rates of particulate biogenic matter simultaneously. The deviations of model fluxes based on nutrient budgets from direct measurements with sediment traps yield an independent estimate of apparent trapping efficiencies. While consistent with hydrographic and nutrient data, model particle fluxes rarely agree with sediment trap data: (1) At shallow water depth ( $\leq 1000 \mathrm{~m})$, sediment trap fluxes are at the average $50 \%$ lower than model fluxes, which confirms flux calibrations using radionuclides; (2) in the very deep traps, model fluxes tend to be lower compared to data, which might be explained by lateral inputs into the traps. According to these model results, particle fluxes from the euphotic zone (EP) into mid water depth are considerably higher and the shallow loop of nutrient is more vigorous than would be derived from sediment trap data. Our results imply that fluxes as collected with sediment traps are inconsistent with model derived long-term mean particle fluxes based on nutrient budgets in the water column. In agreement with recent radionuclide studies, we conclude that reliable export flux estimates can only be obtained from sediment trap data if appropriate corrections are applied.
\end{abstract}

(c) 2003 Elsevier Science B.V. All rights reserved.

Keywords: Inverse modeling; Biogeochemical cycle; Nutrient cycle; Sediment trap; Particulate flux

\section{Introduction}

Modern global ocean carbon cycle models com-

* Corresponding author. Tel.: +49-471-3001511; fax: +49-4713001522 .

E-mail address: usbeck@fielax.de (R. Usbeck). bine physical circulation with biogeochemical processes (e.g., Heinze et al., 1999; Schlitzer, 2000; Joos et al., 1999). This is necessary because air-sea gas 
exchange not only depends on physical solubility of $\mathrm{CO}_{2}$ but also on surface $\mathrm{pCO}_{2}$. Biological production in the euphotic zone (EP) of the ocean lowers the surface $\mathrm{CO}_{2}$ concentration and affects air-sea $\mathrm{CO}_{2}$ fluxes. The removal of particulate nutrients and $\mathrm{CO}_{2}$ from the surface layer is known as "biological pump" (Volk and Hoffert, 1985). The determination of the strength of the "biological pump" requires good estimates for production and remineralization of organic matter.

Eppley and Peterson (1979) estimated export production from a global primary production of $20-45$ to $2-4.5 \mathrm{Gt} \mathrm{C} /$ year. The estimates of primary production have changed very much over the last years (e.g., Berger et al., 1987; Antoine and Morel, 1996; Antoine et al., 1996), with a tendency towards higher values. New methods are currently developed to derive more robust numbers from satellite data (e.g., SeaWiFS, 1998). Additionally, empirical relationships are improved to better estimate export production rates from primary production (Bishop, 1989; Berger and Wefer, 1990; Wassmann, 1993; Wassmann and Slagstad, 1993). It is further very important at which depth nutrients and $\mathrm{CO}_{2}$ are remineralized. Shallow remineralization results in shorter turnover times of nutrients because advection/diffusion processes resupply the dissolved constituents to the surface layer. Deep reaching particle fluxes are essential to remove nutrients and $\mathrm{CO}_{2}$ on longer time scales from the upper ocean.

Sediment trap measurements are the only way to directly record the mass flux, composition, seasonality and inter-annual variability of particle fluxes in the deeper water column. Moorings have been deployed for varying time periods to catch sinking particles. Ideally, at least two traps are positioned such that none of the traps is located neither within the mixed surface layer nor in the nepheloid layer near the sea floor. Usually, deep traps are moored for at least one year to measure the seasonal cycle of particle fluxes. The particles collected in these traps have been used to estimate export of particulate nutrients and $\mathrm{CO}_{2}$ from the euphotic zone. Additionally, the decrease of particle fluxes with depth has been used to derive particle remineralization rates.

However, reliable absolute values for vertical particle fluxes are difficult to obtain from sediment trap data: Horizontal flow velocities in the upper ocean can be relatively high so that tilting of the trap may occur and/or turbulences prevent particle settling into the trap (Baker et al., 1988; Gust et al., 1994; Honjo and Manganini, 1996). Further, in the deeper and near bottom traps, it is likely that the particles collected were not produced in the overlying water column but lateral inputs may occur (Siegel and Deuser, 1997). This would result in the determination of incorrect remineralization rates when comparing upper and lower traps. Sampling efficiencies of sediment traps have been calculated using budgets of radionuclides (e.g., Bacon et al., 1985; Scholten et al., 2001; Yu et al., 2001) or aluminum fluxes (Walsh et al., 1988). Calculation of ${ }^{230} \mathrm{Th}$ budgets is so far the most reliable calibration method for traps deeper than $500 \mathrm{~m} .{ }^{230} \mathrm{Th}$ is produced in the water column by decay of ${ }^{234} \mathrm{U}$ and it is highly particle reactive. Sinking particles scavenge ${ }^{230} \mathrm{Th}$ and the flux at a given depth must (at time scales to years) balance the production rate in the overlying water column. The ${ }^{230} \mathrm{Th}$ flux measured in sediment traps is used to estimate how much of the vertical particle flux is collected in the trap. The calibration of sediment trap data using ${ }^{230} \mathrm{Th}$ budgets yields indications for oversampling resp. undersampling of sediment traps but uncertainties in the corrections remain, which prevents the determination of absolute normalization factors (Bacon et al., 1985; Vogler et al., 1998; Walter, 1998; Henderson et al., 1999). For traps shallower than $500 \mathrm{~m}$, the nuclide ${ }^{234} \mathrm{Th}$ is used for calibration because it is more appropriate due to its shorter lifetime (Buesseler, 1991; Buesseler et al., 1992, 1994).

Even if fluxes are corrected with Th calibrations, budget calculations for global fluxes based on sediment traps are critical. Sediment traps might not provide annual average fluxes even if deployed for a whole year because the inter-annual variation of particle fluxes may be large. Further, sediment trap data are point data and may not be representative for larger areas of the ocean.

In this study, direct flux measurements and biogeochemical flux simulations are compared using an inverse global ocean circulation model and sediment trap data from the Atlantic. The AWI Adjoint Model for Oceanic Carbon Cycling (AAMOCC) used in this study combines ocean circulation with biogeochemical processes determining consumption and redissolution of nutrients (Schlitzer, 2000). The AAMOCC steady state model determines the amount of partic- 
ulate organic carbon (POC) and opal, which must be exported from the euphotic zone to balance advective/ diffusive transports of dissolved nutrients. Nutrient distributions in the deeper water column are used to determine remineralization rates.

An extension of the model now allows to drive the model particle fluxes towards measured fluxes. Different experiments are performed to test whether it is possible to obtain model particle fluxes close to these sediment trap data. Since AAMOCC fluxes are calculated from nutrient budgets, persistent deviations from trap measurements can be used to independently estimate apparent trapping efficiencies. Because the model derived particle fluxes represent time averages, only long-term deployments are included in the comparisons. All traps used in this study have sampling periods of more than 1 year or, in regions of seasonal ice coverage, span the entire ice-free season. Six of the 21 traps provide data for 2 or more years, which helps to eliminate inter-annual changes. It has to be noted, however, that, even for this large collection of trap data that required significant resources for its creation, the sparseness in space remains a problem. Whereas model derived fluxes represent averages over hundreds of kilometers, the sediment trap data essentially represent point measurements. For individual traps, therefore, model/trap discrepancies should be expected and only general trends that hold for more than a single deployment should be considered robust. It is the systematic differences between traps and model results that are the focus of this study.

\section{The adjoint model}

A detailed description of the model used in this study is given in earlier publications of Schlitzer (1993, 1995, 1996, 2000) and de las Heras and Schlitzer (1999). Here, only a short review of the method is given. The model was originally set up by Schlitzer (1993) to derive the mean, large-scale circulation in the Atlantic. The basic concept in the adjoint model is to extract information about ocean circulation from distributions of temperature and salinity. From these data, the velocity field, mixing coefficients and air-sea heat and freshwater fluxes are calculated in a way that assures realistic simulated property fields. The model was expanded by de las Heras and Schlitzer
(1999) to a global domain. In a modification of this adjoint model, dissolved nutrients are used as nonconservative tracers. Depletion of nutrients is interpreted as being removed as biogenic particles, enrichment of nutrients in the deeper water column as remineralization of the sinking particles (Schlitzer, 2000). Physical and biogeochemical process rates are calculated using property distributions of temperature, salinity, $\mathrm{PO}_{4}, \mathrm{NO}_{3}, \mathrm{SiO}_{2}, \mathrm{O}_{2}, \Sigma \mathrm{CO}_{2}$ and alkalinity in the world ocean. The grid used in this study is nonuniform with basic grid cell dimensions between $2^{\circ}$ and $4^{\circ}$ in latitude and $2.5^{\circ}$ and $5^{\circ}$ in longitude. Important areas and areas with strong topography are better resolved, whereas the large ocean basins are mostly covered with grid cells of dimensions $4^{\circ}$ in latitude by $5^{\circ}$ in longitude. The vertical resolution decreases from $60 \mathrm{~m}$ at the surface to about $500 \mathrm{~m}$ at $4000 \mathrm{~m}$ depth. In the model grid, the independent model parameters $p^{*}$ define a current field and a 2D field of gas exchange and vertical particle fluxes (Table 1). The independent model parameters together with hard constraints, namely budget equations for mass, heat, salt and nutrients, yield the property fields of temperature, salinity and dissolved nutrients. The properties are determined by solving a linear system

$A \vec{c}=\vec{q}$

where $A$ is an advection/diffusion matrix, $\vec{c}$ denotes any property of interest and $\vec{q}$ represents source and/or sink terms and boundary fluxes of that property, respectively. Source and sink terms $\vec{q}$ include oxygen and carbon at the surface and describe gas exchange with the atmosphere as well as biological production and remineralization in the water column. Biogenic

Table 1

Independent model parameters

\begin{tabular}{ll}
$\begin{array}{l}\text { Independent } \\
\text { parameters } p^{*}\end{array}$ & Meaning \\
$\overrightarrow{\vec{u}, \vec{v}}$ & $\begin{array}{l}\text { horizontal velocities, defined on all inner } \\
\text { vertical box boundaries } \\
\text { horizontal and vertical mixing coefficients, } \\
\text { globally constant } \\
K_{\mathrm{h}}, K_{\mathrm{v}}\end{array}$ \\
$\operatorname{gex}\left(\mathrm{O}_{2}, \mathrm{CO}_{2}\right)$ & $\begin{array}{l}\text { for exchange rates at sea surface, defined } \\
\text { surface heat fluxes, defined for each column } \\
\text { parameters determining vertical particle fluxes, } \\
\text { defined for each column }\end{array}$ \\
\hline
\end{tabular}


particles are modeled as sources and sinks of dissolved nutrients: Dissolved nutrients are removed from the water column during particle formation (phytoplankton growth in the euphotic zone), whereas remineralization of biogenic particles during sinking and early diagenesis at the sea floor releases nutrients. The data base of temperature, salinity and dissolved nutrients used in this study is described in Schlitzer (2000) and Usbeck (1999). The resulting fields of vertical velocities $\vec{w}$, temperature $T$, salinity $S$ and dissolved nutrients $\mathrm{PO}_{4}, \mathrm{SiO}_{2}, \mathrm{NO}_{3}, \mathrm{O}_{2}, \Sigma \mathrm{O}_{2}$ and alkalinity are called dependent parameters $\tilde{p}$. The dependent parameters $\tilde{p}$ are fully deterministic variables (Table 2 ).

The property fields are then compared with data and deviations are accumulated in a cost function $F\left(p^{*}, \tilde{p}\right)$, which also contains penalty terms for deviations from geostrophic shear, smoothness constraints, etc. (see, e.g., Schlitzer, 1993, 1995; Thacker, 1988). The smaller the cost function, the better the model complies with the desired features (terms in $F$ ). A smaller cost function is achieved in the 'adjoint mode', where new model parameters $p^{*}$ are determined by calculating the gradient of $F$ with respect to the independent model parameters. The complete set of penalty terms of cost function $F$ used in this study is listed further below. Each term in $F$ is multiplied with an individual weight factor and the model is iterated until $F$ is at minimum. Finally, the model solution gives the mean, large-scale ocean circulation together with mean particle fluxes minimizing the cost function $F$.

In this study, the agreement of model distributions and data of temperature, salinity and dissolved nutrients was taken as the main criterion for a 'good' solution. A smaller cost function indicates that the

Table 2

Dependent model parameters

\begin{tabular}{ll}
\hline $\begin{array}{l}\text { Dependent } \\
\text { parameters } \tilde{p}\end{array}$ & Meaning \\
$\vec{w}$ & $\begin{array}{l}\text { vertical velocity, results from mass } \\
\text { conservation, at surface identical with } \\
\text { evaporation and precipitation }\end{array}$ \\
& result from advection/diffusion and \\
$\mathrm{PO}_{4}, \mathrm{NO}_{3}$, & biogenic particle fluxes \\
$\mathrm{SiO}_{2}, \mathrm{TALK}$ & result from advection/diffusion, \\
$\mathrm{O}_{2}, \Sigma \mathrm{CO}_{2}$ & biogenic particle fluxes and \\
& $\begin{array}{l}\text { air-sea exchange rates } \\
\text { result from } \alpha, \beta, s\end{array}$ \\
&
\end{tabular}

model solution yields property fields, which are closer to measurements and thus more realistic.

\subsection{Model particle fluxes}

Particle fluxes are described using functions (Suess, 1980; Martin et al., 1987):

$J(x, y, z)=\alpha(x, y) z^{-\beta(x, y)} \quad z \geq z_{\mathrm{EP}}$

The parameters $\alpha$ and $\beta$ are varied to find optimal sources and sinks in the water column, which minimize misfits between modeled variables and data. For POC, the formulation with equations of type (2) is well established and thus allows direct comparison with estimates from the literature. In contrast, opal dissolution in water column is a major point of interest in recent studies (Ragueneau et al., 2000; Pondaven et al., 2000) and is currently not well understood. In biogeochemical models, these fluxes are sometimes described with exponentially decreasing formulae (Maier-Reimer, 1993; Heinze et al., 1999; Henderson et al., 1999). The exponential form of particle fluxes is more convenient in computational models but nevertheless in this study all components of biogenic material are computed using equations of type (2). Exponentially decreasing particle fluxes correspond to the physical/chemical processes of degradation in the water column: Particle remineralization is proportional to particle abundance. Regarding the fact that biological activity is highest in the upper parts of the ocean where biogenic material is fresher and thus more reactive leads to a preference for the other alternative: Equations $\propto 1 / z$ describe highest redissolution in the upper layers and almost no decrease in the very deep ocean.

In the model, biogenic particles are formed in the two uppermost layers and a particle flux $J(z)$ is defined below the EP, i.e., for $z \geq z_{\mathrm{EP}}$. The flux $J\left(z_{\mathrm{EP}}\right)$ measures the export flux at the base of the euphotic zone and results in a nutrient sink in the upper layers (Fig. 1). In all deeper boxes, the nutrient source $q$ is given by the flux into the box $\left(J_{\mathrm{t}}\right)$ minus the flux out of the box $\left(J_{\mathrm{b}}\right)$. In this way, all sources of dissolved nutrients are gradually calculated top down the water column.

$q=J_{\mathrm{t}}-J_{\mathrm{b}}$

In the lowest box, sediment accumulation is modeled with particle flux $J(S)$ (flux to the sediment). A 


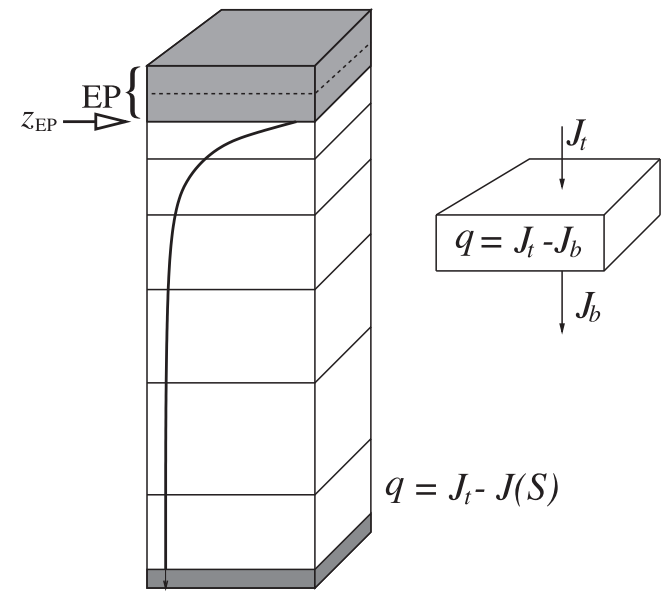

Fig. 1. Model water column. Sources and sinks of dissolved nutrients in a box are defined as the flux through the top surface $J_{\mathrm{t}}$ minus the flux through the bottom surface $J_{\mathrm{b}}$.

fraction $s$ of the incoming flux $\left(J_{\mathrm{t}}\right)$ is accumulated in the sediment, while the rest is remineralized. The parameter $s \leq 1$ is calculated by the model. The sum of the nutrients globally accumulated into the sediments is resupplied to the ocean by riverine inputs.

$J(S)=s J_{\mathrm{t}}$

\subsection{Cost function}

Most terms of the cost function are discussed in detail in earlier publications of Schlitzer (1993, 1995, 2000) and Usbeck (1999). Here, only a short review of terms used in this study is given.

(1) Deviations from initial geostrophic shear

Outside the equatorial band $\left(10^{\circ} \mathrm{S}-10^{\circ} \mathrm{N}\right)$, the vertical shear of the horizontal velocities is required to be close to original geostrophic shear computed from geostrophic flow calculations.

(2) Deviations of mixing coefficients from 'mixing coefficient data'

Mixing coefficients are kept close to mixing coefficients from earlier model calculations especially performed to determine best values.

(3) Deviations from data

Deviations of model fields to measurements are computed pointwise for data of temperature, salinity, oxygen, phosphate, nitrate, silicate, total carbon and total alkalinity. For the same properties, the bias is calculated by computing the systematic deviation within the neighborhood of a box.

(4) Deviations from sediment trap data In boxes where trap data exist, the deviations of model fluxes to sediment trap data are calculated. The general form of this term is analogous to other terms penalizing deviations to data.

(5) Smoothness constraints

The second derivative of parameters is used to enforce spatial smoothness of vertical velocities $\vec{w}$, surface heat fluxes, gas exchange rates and biogeochemical parameters.

(6) Deviations from a priori volume transports

Deviations from a priori volume transports are penalized by integrating the horizontal velocities over prescribed surfaces and calculating the differences to a priori transports $T$. Prescribed top-to-bottom flows were the same for all experiments and are summarized in Table 3. Note that a priori transport requirements are implemented by weak constraints and the model may deviate from these values.

\subsection{Sediment trap data}

The sediment trap data used in this study are annual mean particle fluxes of organic carbon and opal derived from time series of the German Joint Research Project 261 (SFB261), the Bermuda Atlantic Time-Series Study (BATS, 1998; Deuser et al., 1981) and "JGOFS North Atlantic Bloom Experiment" (NABE, 1998; Honjo and Manganini, 1993). The data from SFB261 are mostly published (Fischer et al., 1988, 1996a,b, 2000; Fischer and Wefer, 1996; Wefer and Fischer, 1991). For the comparison with model

Table 3

A priori volume transports prescribed for all experiments

\begin{tabular}{lcl}
\hline Area & $T(\mathrm{~Sv})$ & Notes \\
\hline Exchange with Mediterranean Sea & 0 & open model boundary \\
Exchange with Red Sea & 0 & open model boundary \\
Exchange with Persian Gulf & 0 & open model boundary \\
Baffin Bay export of Arctic waters & 1 & \\
Florida current & 30 & \\
Drake passage & 130 & \\
NADW across the equator & -18 & \\
Indonesian passage & -10 & \\
\hline
\end{tabular}

NADW: North Atlantic Deep Water. 
particle fluxes (representing long-term mean fluxes), mean annual fluxes were calculated from the raw data of POC and opal. For moorings that were deployed for whole years (cf. Table 4), annual mean fluxes are determined directly by integrating measured fluxes. Other moorings with short or irregular sampling were treated specially:

- KN1 trap was moored directly off Kap Norvegia, Antarctica. Data were collected in a period of 53 days only. Sea ice is present most of the year and thus the flux collected within 53 days of ice-free sea surface was taken as the integrated annual flux.

- EA8 (Eastern Equatorial Atlantic) was deployed for 296 days. Since the seasonality is very low at the equator, the flux was multiplied by 365/296.

- CV1 (181 days) and CV2 (498 days) (Cape Verde Islands) were deployed in a series. Integrated flux (679 days) was multiplied by $365 / 679$.

- CB2 (374 days) and CB3 (379 days) (Cape Blanc) were also deployed in a series. Integrated flux (718 days) was multiplied by $365 / 718$.

- BO1 (Bouvet Island) was deployed for 460 days between December 1990 and April 1992. This trap shows high seasonality with high particle fluxes from January to the end of March and low fluxes otherwise. The inter-annual variation was relatively high and two high-productive sequences were covered by that time series. The data were averaged (multiplied by 365/460) in order to get a better estimate for annual fluxes.

- WS1 (Weddell Sea) shows a seasonal signal with high particle fluxes in February. The mean particle flux was taken from Fischer et al. (1988).

- BATS traps were deployed for up to 2 years. Here, seasonality was low. Data were averaged over the whole period.

- NABE traps show a seasonal signal, mean values were taken from Honjo and Manganini (1993).

Almost all traps are long-term moored traps, BATS being the only exception. Sediment traps at Bermuda are floating, surface-tethered traps (VERTEX style). Table 4 lists data of POC and biogenic opal fluxes in sediment traps in the Atlantic assimilated into the model database. The positions of the sediment traps listed in Table 4 are shown in Fig. 2. In total, the data set consists of 21 sediment trap deployments covering a large part of the Atlantic

Table 4

Annual particle fluxes of POC and opal as measured in the sediment traps used in this study

\begin{tabular}{|c|c|c|c|c|c|c|}
\hline Trap & Latitude $\left({ }^{\circ} \mathrm{N}\right)$ & Longitude $\left({ }^{\circ} \mathrm{E}\right)$ & Depth (m) & Deployment (days) & POC (mol/m²/year) & Opal (mol $/ \mathrm{m}^{2} /$ year $)$ \\
\hline KN1 & -71 & -12 & 250 & 53 & 0.1583 & 0.533 \\
\hline WS3 & -65 & -3 & 360 & 368 & 0.1942 & 0.413 \\
\hline KG1 & -62 & -58 & 1600 & 360 & 0.3583 & 0.65 \\
\hline WS1 & -62 & -35 & 900 & 418 & 0.0025 & 0.005 \\
\hline BO1 & -54 & -3 & 453 & 460 & 0.225 & 0.893 \\
\hline PF3 & -50 & 6 & 700 & 366 & 0.2808 & 0.398 \\
\hline NU2 & -29 & 13 & 768 & 361 & 0.5762 & 0.007 \\
\hline WR21 & -20 & 9 & 1654 & 360 & 0.3142 & 0.051 \\
\hline WA3u & -8 & -28 & 671 & 350 & 0.0792 & 0.007 \\
\hline WA31 & -8 & -28 & 5031 & 350 & 0.0246 & 0.005 \\
\hline WA41 & -4 & -26 & 4555 & 375 & 0.0813 & \\
\hline EA8m & -6 & -9 & 1833 & 296 & 0.1967 & 0.03 \\
\hline GBZ51 & -2 & -10 & 3382 & 360 & 0.1917 & 0.097 \\
\hline GBN31 & 2 & -11 & 3965 & 361 & 0.181 & 0.077 \\
\hline CV1u, CV2u & 11.5 & -21 & 1021 & 679 & 0.2239 & 0.0582 \\
\hline CV11, CV21 & 11.5 & -21 & 3075 & 679 & 0.106 & 0.0434 \\
\hline $\mathrm{CB} 2 / 3$ & 21 & -20 & 3525 & 718 & 0.5042 & 0.095 \\
\hline BATS1 & 31.5 & -64.1 & 150 & 785 & 0.776 & \\
\hline BATS4 & 31.5 & -64.1 & 400 & 314 & 0.374 & \\
\hline NABE34 & 34 & -21 & 4500 & 728 & 0.075 & 0.033 \\
\hline NABE48 & 48 & -21 & 3700 & 728 & 0.0833 & 0.1 \\
\hline
\end{tabular}


including high productive regions as the coastal upwelling regimes as well as oligotrophic sites in the open ocean.

\subsection{Experiments}

Several numerical experiments have been carried out to obtain optimum ocean circulation and biogeochemical particle fluxes. Main objective in all model runs was to find parameters for export production, remineralization and accumulation rates of biogenic particles, which are consistent with nutrient data. The weights of the terms in the cost function were chosen very similar as in Schlitzer's (2000) experiments. Largest weights were applied for the geostrophic constraint and deviations from observed fields.

The sensitivity of model particle fluxes to the assimilation of sediment trap data were investigated. Sediment trap data were assimilated in some model simulations in order to test whether model particle fluxes could be made consistent with particle fluxes measured in sediment traps. The constraint to reproduce sediment trap data and smoothness constraints are varied in the individual experiments. The individual experiments presented here are:

- I (reference run): A reference experiment was performed in the model's most simple mode. No sedi-

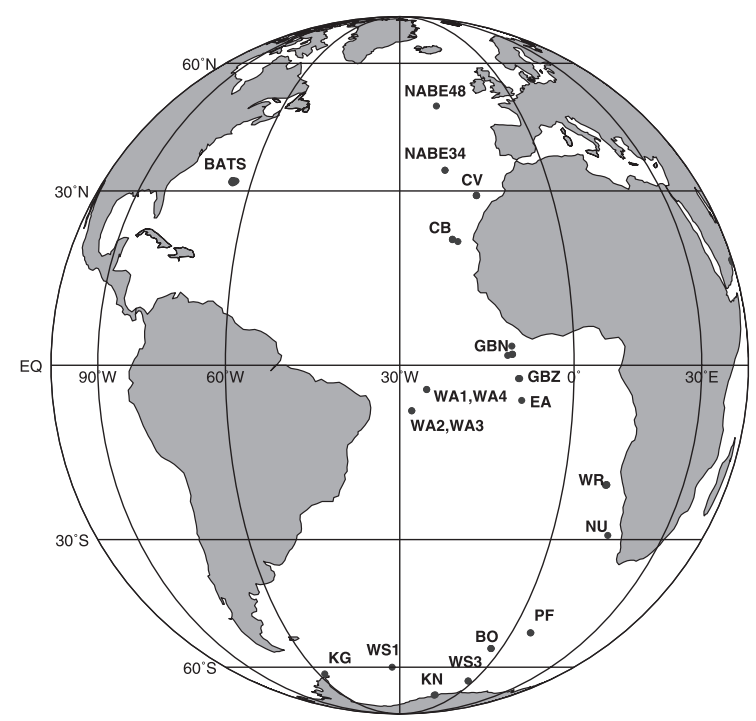

Fig. 2. Positions of sediment traps in the Atlantic used in this study.
Table 5

Summary of the different experiments

\begin{tabular}{lll}
\hline Name & Trap data & Initial values for all parameters \\
\hline I & no & from Schlitzer (2000) \\
IIa & yes & from Schlitzer (2000) \\
IIb & yes & from Experiment IIa \\
III & no & from Experiment IIb \\
\hline
\end{tabular}

ment trap data are assimilated. Fluxes are exclusively determined by budgets of dissolved nutrients and smoothness constraints. This model setup is comparable with Schlitzer's (2000) experiments.

- II: In Experiment II, sediment trap data (Table 4) were included as soft constraints.

- a: In a first run, the weight factors for the sediment trap data constraints were set to very high values to force the model to reproduce the data. All other weight factors were kept as in Experiment I. This led to unrealistic patterns in the parameter fields, the parameters changed at the trap positions only while the neighborhood remained unaffected.

- b: A subsequent run was performed to smoothen out the parameter fields from Experiment IIa. Therefore, the weight factors for the sediment trap data constraints were reduced and smoothness constraints for the biogeochemical parameters were increased.

- III: After a smooth solution of Experiment II was gained, weight factors for the reproduction of sediment trap data were reduced by 23 orders of magnitude, i.e., the model was effectively no longer forced to reproduce the data.

Initial fields for parameters $\alpha, \beta, s$ and the flow field were taken from Schlitzer (2000) and were identical for Experiments I and II. The experiments were iterated until the cost function was at minimum. The experiments are summarized in Table 5.

\section{Results}

Experiments I and IIa were initialized with the same circulation and the same fields of biogeochemical parameters. In both experiments, the general 
agreement of modeled distributions of temperature, salinity, $\mathrm{CO}_{2}, \mathrm{O}_{2}$ and nutrients compared to data is very good and in general, biases of mean concentrations are negligible (Table 6). The RMS deviations are also rather small compared to mean concentrations. In general, larger deviations are restricted to the upper ocean. For instance, the standard deviation for temperature is about $1.9{ }^{\circ} \mathrm{C}$ at $100 \mathrm{~m}$ depth, but about $0.15^{\circ} \mathrm{C}$ only at $4000 \mathrm{~m}$. A discussion of error analysis for this high-dimensional problem is given in Schlitzer (2000). The flow field is comparable to results presented in earlier publications of de las Heras and Schlitzer (1999) and Usbeck (1999) and therefore not presented in this paper. The globally integrated export of particulate organic carbon out of the euphotic zone in all experiments amounts to approximately $10 \mathrm{Gt} \mathrm{C/}$ year. This is in good agreement with results from dynamic ocean models where export production is calculated from concentrations of dissolved nutrients using Michaelis-Menten kinetics. In these models, export production ranges from 8-10 (Yamanaka and Tajika, 1996, 1997) and 8.8 (Heinze et al., 1999) to about 7-13 Gt C/year (Najjar et al., 1992).

\subsection{Experiment I}

The production of biogenic particles in the model occurs in the uppermost two layers of the model and the export flux is defined at $z_{\mathrm{EP}}=133 \mathrm{~m}$ depth. Figs. 3 and 4 show the export fluxes of POC and opal in the Atlantic from Experiment I.

The export production of organic carbon is high in the equatorial and eastern margin upwelling regimes and along about $50^{\circ} \mathrm{S}$. In these areas, maps of chlorophyll measurements indicate enhanced produc-

Table 6

Global mean concentrations from observations and model and overall standard deviations for all modeled variables from Experiment I

\begin{tabular}{lccc}
\hline Property & Data & Model & RMS \\
\hline Temperature & 3.66 & 3.54 & 1.17 \\
Salinity & 34.72 & 34.72 & 0.14 \\
$\mathrm{O}_{2}$ & 171.2 & 172.0 & 19.5 \\
$\mathrm{PO}_{4}$ & 2.12 & 2.14 & 0.2 \\
$\mathrm{NO}_{3}$ & 30.00 & 30.77 & 3.17 \\
$\mathrm{SiO}_{2}$ & 87.41 & 89.05 & 9.85 \\
$\Sigma \mathrm{CO}_{2}$ & 2244.4 & 2259.8 & 20.3 \\
$\mathrm{TALK}$ & 2361.7 & 2367.6 & 12.7 \\
\hline
\end{tabular}

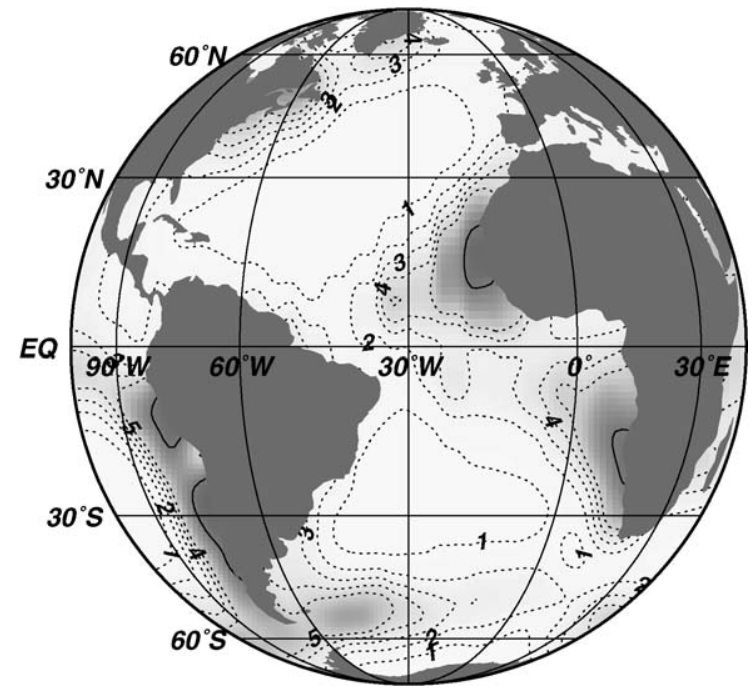

Fig. 3. Export production of organic carbon ( $\mathrm{mol} \mathrm{C} / \mathrm{m}^{2} /$ year) at 133 $\mathrm{m}$ depth from Experiment I.

tivity, which lends to confidence in the model. Even if there is no simple relationship between primary production and particle export, POC export is only expected where primary production is high (Buesseler, 1998; Fischer et al., 2000). Opal exports are low in the tropical and subtropical Atlantic and increase to about $4.5 \mathrm{~mol} / \mathrm{m}^{2} /$ year at about $55^{\circ} \mathrm{S}, 10^{\circ} \mathrm{E}$. This high export fluxes of opal is the maximum in the Atlantic

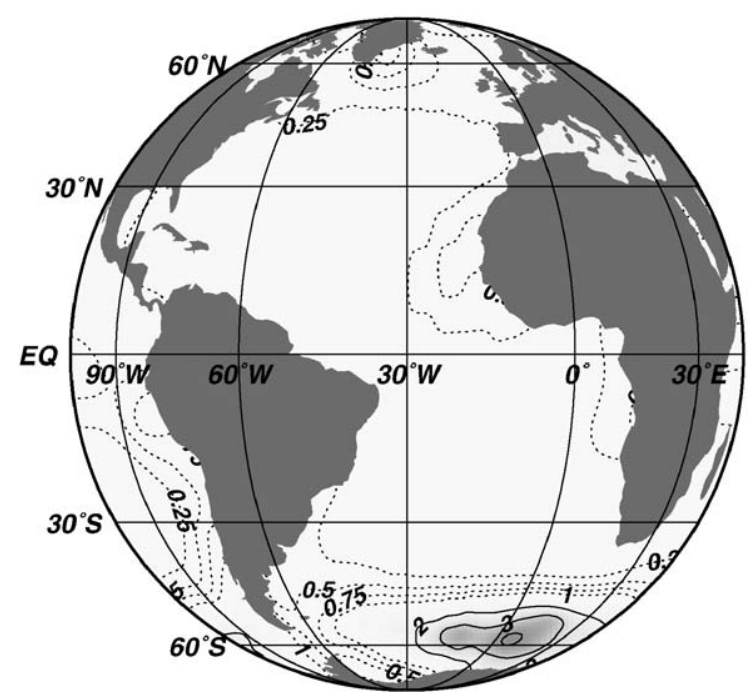

Fig. 4. Export production of opal ( $\mathrm{mol} \mathrm{Si} / \mathrm{m}^{2} /$ year) at $133 \mathrm{~m}$ depth from Experiment I. 
sector of the Southern Ocean. In most areas, the export is much lower. High productivity for opal was also observed in the permanently open ocean zone (POOZ) south of the Polar Frontal Zone (PFZ) in the Indian sector of the Southern Ocean by Pondaven et al. (2000). Based on nutrient data, they found the mean annual opal production rates of $3.34 \pm 0.54$ $\mathrm{mol} / \mathrm{m}^{2} /$ year POOZ.

The particle fluxes together with the physical flow field yield temperature, salinity, $\mathrm{CO}_{2}, \mathrm{O}_{2}$ and nutrient simulations close to measurements (Table 6). In that sense, the particle fluxes from Experiment I are considered as a reasonable solution.

Particle fluxes from Experiment I at the respective trap locations are in the same order of magnitude as measurements. Modeled POC fluxes lie between 0 and $0.72 \mathrm{~mol} / \mathrm{m}^{2} /$ year, and the maximal trap fluxes amount to $0.78 \mathrm{~mol} / \mathrm{m}^{2} /$ year. With two exceptions, model opal flux range is also similar $\left(0-0.8 \mathrm{~mol} / \mathrm{m}^{2} /\right.$ year) as sediment trap fluxes ranging from 0 to 0.9 $\mathrm{mol} / \mathrm{m}^{2} /$ year.

However, a detailed comparison of model fluxes and measurements reveals systematic deviations at shallow (0-1000 m, Fig. 5) and deep (>1000 m, Fig. 6) trap depths. At the locations of the shallow sediment traps, model POC fluxes ( $y$-axis) are significantly higher than direct measurements ( $x$-axis). The trap BATS at 150 and $400 \mathrm{~m}$ appears as the only

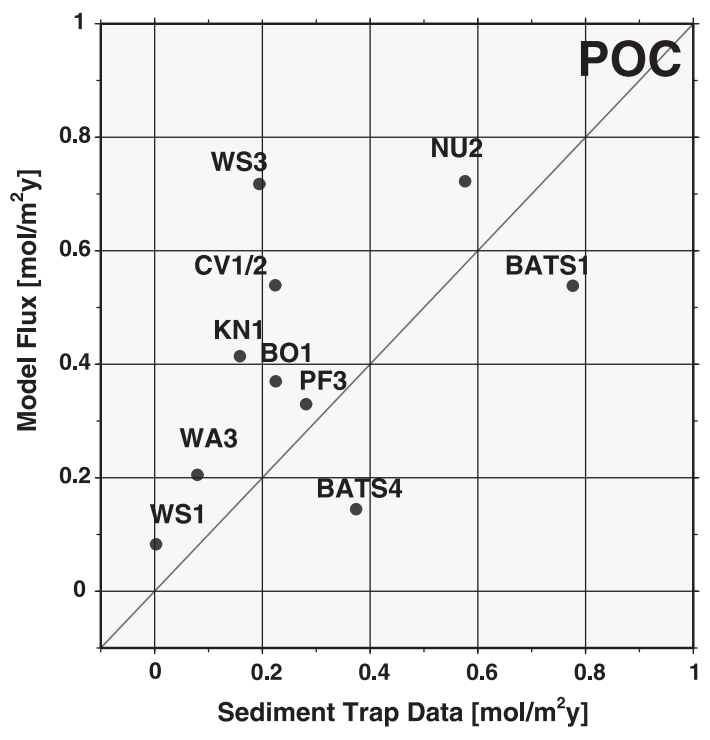

exception showing higher particle fluxes compared to model fluxes (Fig. 5, left). Thus, the model results based on nutrient budgets indicate higher particle fluxes than found in sediment traps at all locations except BATS. Particulate opal fluxes in the shallow traps show the same trend (Fig. 5, right). Here, all modeled fluxes are higher than measured in sediment traps (no opal data were available for the BATS trap). Fluxes higher than $2.5 \mathrm{~mol} / \mathrm{m}^{2} /$ year only occur in the model; none of the direct measurements exceeds 1 $\mathrm{mol} / \mathrm{m}^{2} /$ year. In summary, particles collected in shallow sediment traps appear to be low compared to fluxes calculated from nutrient budgets.

In contrast, for the deep traps model, POC fluxes are generally lower compared to measurements (Fig. 6 , left). Deviations of model opal fluxes (right) do not seem to be systematic.

\subsection{Experiment II}

To test whether the model could be made consistent with sediment trap data, the flux data were included as soft constraints by adding terms penalizing deviations of model fluxes from flux data to the cost function and applying large weight factors. This setup of the cost function would reduce particle fluxes at the positions of the sediment traps. Since the other terms in the cost function are still active with the same weights as in

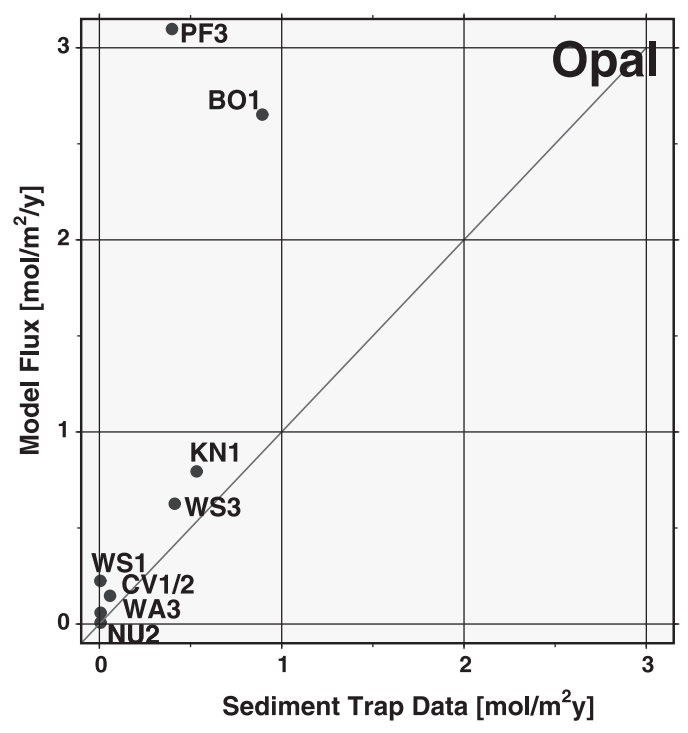

Fig. 5. Model POC and opal fluxes from Experiment I compared to sediment trap data for traps shallower than $1000 \mathrm{~m}$. 

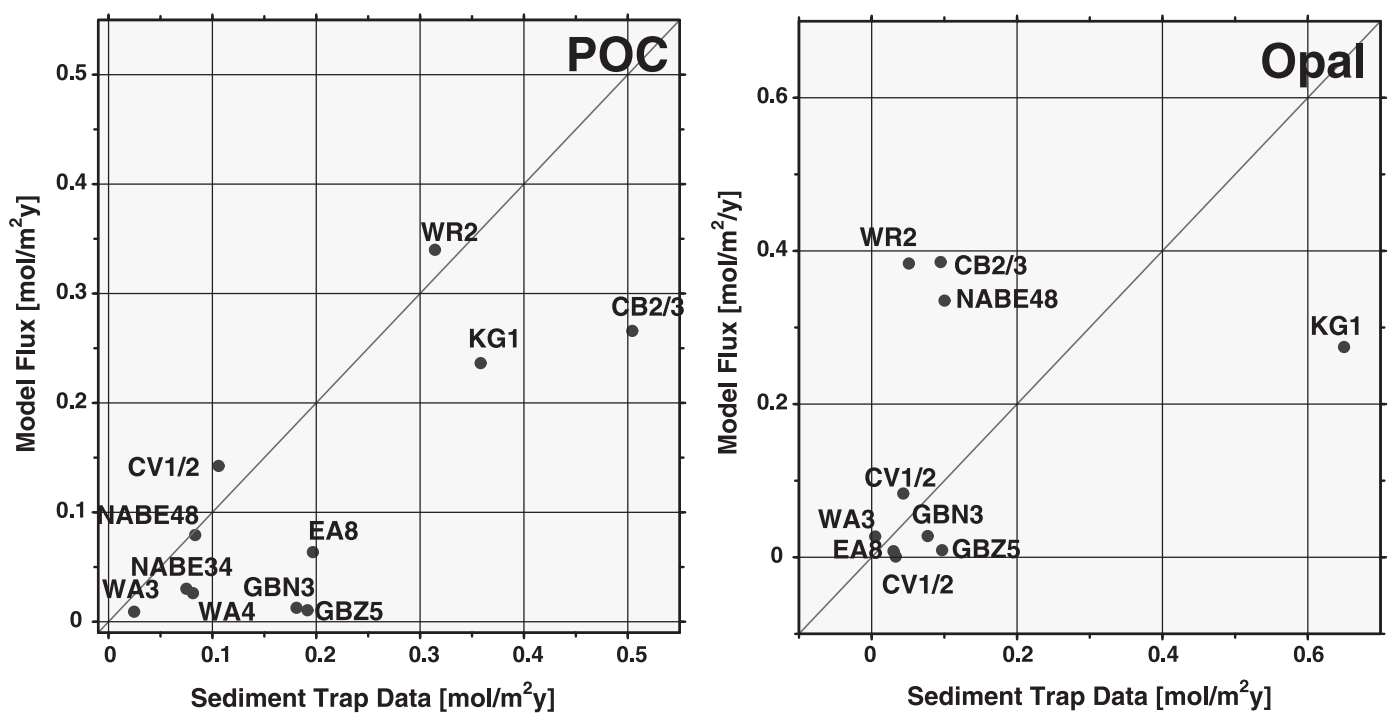

Fig. 6. Model POC and opal fluxes from Experiment I compared to sediment trap data for traps deeper than $1000 \mathrm{~m}$.

Experiment I, the parameter fields are forced to accommodate similar large-scale transports, small model-data misfits and smoothness. If a solution exists that accommodates all constraints while favoring the lower fluxes at the sediment trap positions, the model would readjust the parameters over larger scales.

The solution of model Experiment II indeed resulted in very small discrepancies between modeled fluxes and sediment trap data. The change in particle flux through the water column is illustrated with examples of POC fluxes (Experiments I and IIa). Fig. 7 shows model POC fluxes at the locations of all shallow sediment traps for Experiments I (solid line) and IIa (dashed line). Sediment trap data are indicated as filled marks. In most examples given in Fig. 7, fluxes from Experiment I are higher than fluxes from Experiment IIa and sediment trap data. Export production in Experiment I is up to a factor of about 9 higher (trap WA3, Fig. 7(c)) than in Experiment IIa. The only exception is found for the BATS trap (Fig. 7(a)). Here, model fluxes are smaller than measurements in both experiments. Due to higher export production and sometimes also deeper remineralization, fluxes reaching the deep ocean are higher in Experiment I. In other words, the 'biological pump' is more effective in Experiment I. But the solid lines do not match the sediment trap data and are thus not in agreement with direct flux measurements. Particle fluxes from Experiment IIa (dashed lines) almost exactly match the sediment trap data.

Model fluxes of Experiment IIa could be considered to be a good representation of sediment trap data. However, inspection of the model export production and remineralization scale length revealed that in this solution, the biogeochemical parameters were changed only locally at the positions of sediment traps, whereas the remaining regions were left unchanged. In Experiment IIa, large and unrealistic discontinuities in the distributions of the biogeochemical parameters occur, whereas Experiment I exhibits smooth distributions (Figs. 3 and 4). As mentioned above, the almost exact match of model fluxes and sediment trap data is not unsurprising due to the large weight factors. The abrupt change in the parameter fields at the positions of the sediment trap indicates that an increase of the penalty terms associated with the other constraints together with the decrease of the terms belonging to the sediment trap data leads to an overall smaller cost function. More exact, the smoothness constraints for the parameters $\alpha$ and $\beta$ in the vicinity of the sediment traps together with increased modeldata misfits for dissolved nutrients do not break even with small discrepancies between model fluxes and sediment trap data. An overall smooth solution with reduced particle fluxes in the upper water column was not found. Thus, Experiment IIa is not considered to 
(a) BATS: Bermuda

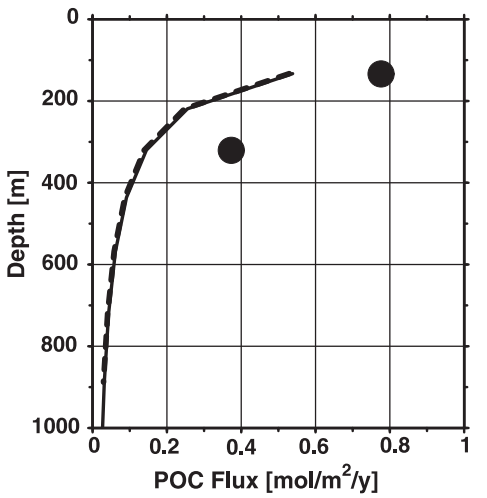

(d) NU2: Namibia Upwelling

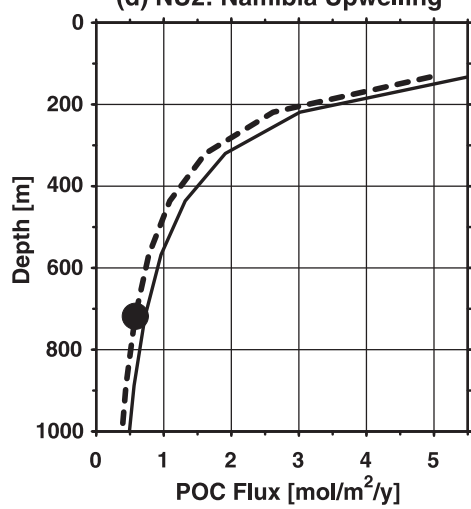

(g) WS1: Weddell Sea (West)

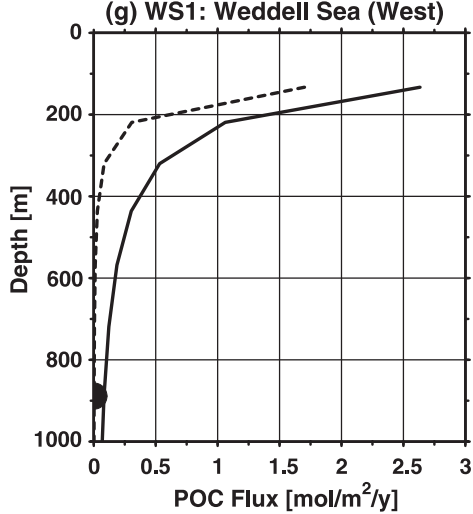

(b) CV: Cape Verde

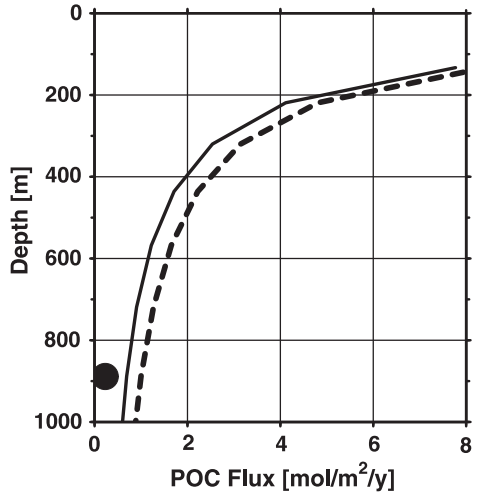

(e) PF3: Polar Front

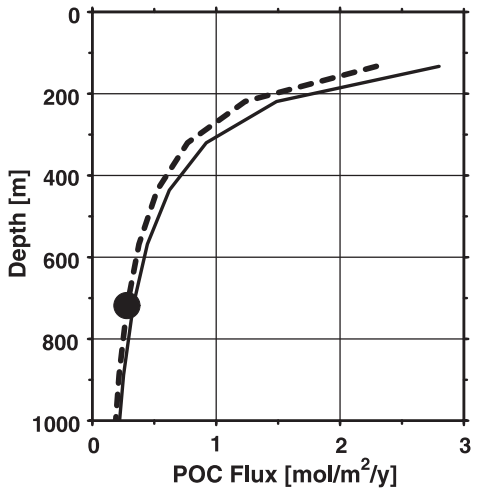

(h) WS3: Weddell Sea

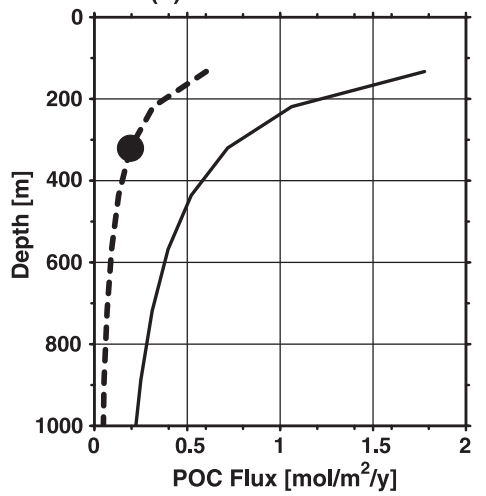

(c) WA: West Atlantic

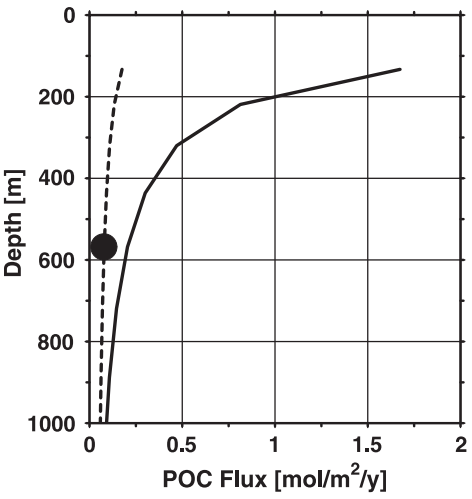

(f) BO: Bouvet Island

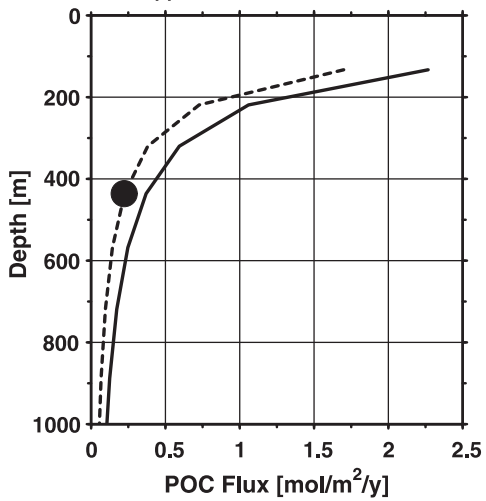

(i) KN: Kap Norvegia

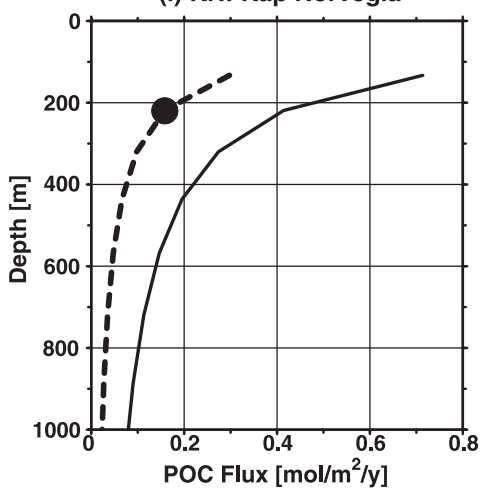

Fig. 7. POC model fluxes from Experiments I (solid) and IIa (dashed) for all locations of shallow $(<1000 \mathrm{~m})$ traps. Sediment trap data are displayed as filled marks.

be a satisfying solution because of its failure to accommodate sediment trap fluxes over larger spatial scales.

Experiment IIb, a subsequent model run, was performed to 'smoothen out' the parameter fields.
Weight factors of smoothness constraints for export production and remineralization were increased to avoid abrupt changes as occurred in Experiment IIa, whereas weight factors for sediment trap data were reduced. The discontinuities in the resulting parameter 
fields are much weaker compared to Experiment IIa. The resulting particle fluxes for the examples above are between fluxes of Experiments I and IIa; i.e., compared with Experiment IIa, export production increases and particle fluxes again reach deeper layers of the ocean. Sediment trap data are not as well reproduced as in Experiment IIa. Experiment IIb constitutes a compromise between Experiments I and IIa, which yields smooth parameter fields, while the sediment trap data are better reproduced than in Experiment IIa.

\subsection{Experiment III}

The solution of Experiment IIb is used in a final experiment to test whether IIb persists if the model is no longer forced to reproduce the trap data. Therefore, based on the smooth solution of Experiment IIb, the constraint to reproduce sediment trap data was effectively removed. This led to larger model particle fluxes (similar to Experiment I) at most of the sediment trap positions. The minimum of the cost function acquired in Experiment $\mathrm{IIb}$ is thus no stable overall minimum, but only holds if the trap constraint is applied. Nutrient data and the flow field again drive the model towards higher particle fluxes. Particle fluxes derived in Experiments IIb and III are not shown in detail. Model particle fluxes from these experiments generally are between solutions from Experiments I and IIa.

\section{Discussion}

The AAMOCC model was used to calculate annual mean particle fluxes from nutrient budgets while being consistent with ocean dynamics. The experiments performed during this study resulted in property distributions of temperature, salinity and nutrients very close to measurements (Table 6). The globally integrated POC fluxes are within independent estimates of dynamic ocean models and the patterns of export production of POC and opal appear to be realistic. A comparison of model fluxes from Experiment I and fluxes as measured in sediment traps revealed that the model fluxes at shallow trap locations are in the same order of magnitude but systematically higher than measurements.
In principle, the model fluxes at shallow depth may be different from direct flux measurements due to an inappropriate representation of the regime at the specific sediment trap location. The model fluxes are calculated from long-term steady state nutrient distributions and thus describe long-term mean particle fluxes, which balance the nutrient budgets in the model's resolution. The nutrient fluxes (both particulate and dissolved) at a location of a trap deployment may vary from year to year and on smaller spatial scales, which is not resolved in the model. Also, the statistical variance of the hydrographic and nutrient data in the model database results in uncertainties of the model particle fluxes. On the other hand, one would expect that the deviations of model fluxes from measurements are random, if the model fluxes were wrong due to the coarse model resolution or due to statistical reasons.

The fluxes as measured in sediment traps were assimilated into the model database in order to test whether a model solution is achievable, which is consistent with the direct flux measurements (Experiment II). The minimum found in Experiment II with reduced particle fluxes in the upper water column was not stable. The systematic deviations of model fluxes from sediment trap data reappeared when the constraint to reproduce sediment trap data was removed. With only one exception, all model fluxes at sediment traps shallower than $1000 \mathrm{~m}$ again became higher than measurements. We conclude that the small flux values obtained with sediment traps in the upper $1000 \mathrm{~m}$ of the water column are actually inconsistent with the observed nutrient fields and steady-state nutrient budgets.

We select Experiment I to be discussed with respect to its relation to sediment trap data. This reference experiment was run without the interference of sediment trap data and thus allows to compare particle flux estimates based on independent methods. We use the model particle fluxes calculated from nutrient budgets in Experiment I to calculate 'apparent trapping efficiencies'. The fluxes measured in sediment traps are divided by model fluxes at the respective sediment trap locations. Table 7 gives the apparent trapping efficiencies according to our model and also trapping efficiencies from ${ }^{230} \mathrm{Th}$ calibrations, which are discussed further below. First, we focus on the 'apparent trapping efficiencies' of our model Experiment I. 
Table 7

Modeled annual particle fluxes of POC and opal, ${ }^{230} \mathrm{Th}$ trapping efficiencies and "average apparent trapping efficiencies" from model Experiment I

\begin{tabular}{|c|c|c|c|c|c|}
\hline \multirow[t]{2}{*}{ Trap } & \multirow{2}{*}{$\begin{array}{l}\text { Model POC } \\
\text { flux }\left(\mathrm{mol} / \mathrm{m}^{2} / \text { year }\right)\end{array}$} & \multirow{2}{*}{$\begin{array}{l}\text { Model opal } \\
\text { flux (mol/m²/year) }\end{array}$} & \multirow{2}{*}{$\begin{array}{l}\text { Trapping efficiencies } \\
\text { from }{ }^{230} \mathrm{Th} r_{230} \mathrm{Th}(\%)\end{array}$} & \multicolumn{2}{|c|}{ 'Apparent trapping efficiencies', this study } \\
\hline & & & & $r_{\mathrm{POC}}(\%)$ & $r_{\text {Opal }}(\%)$ \\
\hline \multicolumn{6}{|l|}{ Shallow } \\
\hline BATS1 & 0.538 & & & 144 & \\
\hline KN1 & 0.414 & 0.794 & & 38 & 67 \\
\hline BATS4 & 0.145 & & & 258 & \\
\hline WS3 & 0.718 & 0.627 & $85^{1}$ & 27 & 66 \\
\hline $\mathrm{BO} 1$ & 0.370 & 2.652 & $48^{1}$ & 61 & 34 \\
\hline WA3 & 0.205 & 0.058 & & 39 & 12 \\
\hline NU2 & 0.722 & 0.0068 & & 80 & 103 \\
\hline PF3 & 0.330 & 3.097 & $<44^{2}$ & 85 & 13 \\
\hline $\mathrm{CV} 1 / 2$ & 0.539 & 0.146 & $9-10^{4}$ & 42 & 40 \\
\hline WS1 & 0.083 & 0.224 & & 3 & 2 \\
\hline Mean & & & & 78 & 42 \\
\hline \multicolumn{6}{|l|}{ Deep } \\
\hline KG1 & 0.236 & 0.275 & $184^{1}$ & 152 & 237 \\
\hline WR2 & 0.340 & 0.384 & & 93 & 13 \\
\hline EA8 & 0.064 & 0.008 & & 309 & 379 \\
\hline GBZ5 & 0.011 & 0.009 & & 1808 & 1024 \\
\hline $\mathrm{CB} 2 / 3$ & 0.266 & 0.385 & & 190 & 24 \\
\hline GBN3 & 0.013 & 0.028 & & 1415 & 280 \\
\hline $\mathrm{CV} 1 / 2$ & 0.142 & 0.085 & $20-23^{4}$ & 74 & 52 \\
\hline WA4 & 0.026 & & & 310 & \\
\hline WA3 & 0.009 & 0.027 & & 265 & 18 \\
\hline NABE34 & 0.030 & 0.001 & $91-123^{2,3,4}$ & 248 & 284 \\
\hline NABE48 & 0.079 & 0.335 & $70-135^{2,3,4}$ & 105 & 30 \\
\hline Mean & & & & 420 & 232 \\
\hline
\end{tabular}

${ }^{230}$ Th-trapping efficiencies ( $r_{230}$ Th from literature: (1) Walter et al. (2001), (2) Yu et al. (2001), (3) Antia et al. (2001), (4) Scholten et al. (2001). $r_{\text {POC/Opal }}$ is the ratio of measured (cf. Table 4) and modeled annual particle fluxes at the respective trap positions.

The particle fluxes in the shallow traps measure between 2\% (opal at trap WS1) and 258\% (POC at trap BATS4) of the model fluxes.

Provided that the model fluxes are realistic, average apparent trapping efficiencies calculated with the AAMOCC model indicate whether the flux measured in a sediment trap is representative for the mean annual fluxes in the region of deployment.

It is very well known that under certain conditions, sediment trap data bear relatively high errors and determining trapping efficiencies was identified to be a major problem limiting the quantitative interpretation of sediment trap data. Trapping efficiencies can decrease in shallower depths due to relatively high flow velocities around the traps combined with lower settling velocities of the particles in the water column (Gust et al., 1994; Baker et al., 1988). In addition, 'swimmers' can enter the traps to feed on the collected material mainly in shallower depths. Nekton entering the traps is commonly removed from the samples but this might cause some biasing. Further, the material collected remains in the sampling device for weeks to months and degradation occurs. Any of the processes mentioned above or a combination of all of them may indeed reduce total particle fluxes in traps deployed in the upper part of the water column.

The mean apparent trapping efficiency calculated from Experiment I is about $78 \%$ for POC and $42 \%$ for opal. Except at trap BATS, the apparent trapping efficiencies are smaller than $100 \%$, i.e., fluxes from all other sediment traps shallower than $1000 \mathrm{~m}$ are lower than our model fluxes. The exception at the BATS trap is somewhat surprising because other studies testified-by means of ${ }^{234} \mathrm{Th}$ calibrations 
(Buesseler, 1991) and calculation of budgets of dissolved carbon (Michaels et al., 1997) — that the BATS traps are rather missing some of the vertical flux. In the AAMOCC model, low fluxes are presumably caused by the low phosphate and nitrate concentrations of the surface water (and its sources) of this area where downwelling occurs over larger scales. The Bermuda islands are ignored in the model topography and thus small-scale features important for the particle fluxes close to the islands may be overseen.

The difference between the mean apparent trapping efficiencies of carbon and opal is mainly due to the high opal fluxes required by the model at the traps BO and PF (Fig. 5). These traps are associated with the Antarctic Circumpolar Current (ACC) and, here, strong lateral advection of particles could play a significant role. Fine opal particles, such as small diatoms, might not be collected by the sediment traps due to elevated current velocities.

At the deep trap positions, the apparent trapping efficiencies are between 13\% (opal at trap WR2) and $1808 \%$ (opal at trap GBZ5). Some of the model particle fluxes seem to be significantly lower compared to sediment trap data (for instance, GBZ and GBN) resulting in very large mean efficiencies. These deviations are explained by almost zero model fluxes at these positions, while some material was found in the traps (Fig. 6). Absolute deviations are in the same order of magnitude or smaller as for the shallow traps but model fluxes are almost one order of magnitude smaller than fluxes as determined with sediment traps.

For the deep traps, mean apparent trapping efficiencies amount to $452 \%$ for organic carbon and $234 \%$ for opal. These high values are strongly affected by the traps GBZ and GBN. Most of the apparent trapping efficiencies are much lower. If both traps GBZ and GBN are excluded, mean apparent trapping efficiencies amount to $194 \%$ for POC and $130 \%$ for opal. It should be noted again that the absolute deviations at the deep trap positions are smaller than for the shallow traps. Further, the model is much less sensitive to particle remineralization in the deeper water column because of the approximation with a power-law for the whole water column: Strong gradients in the nutrient distributions generally occur in the upper ocean. The parameter $\beta$ in the description of particle fluxes with Suess-type functions is mainly controlled by these gradients. In the deeper ocean, particle fluxes and remineralization are much less and does not alter the nutrient distributions significantly. A transition to another parameterization for particle remineralization in the very deep ocean would not change the fit with data of dissolved nutrients very much but could make a big change in the model particle fluxes. Thus, deviations between deep model particle fluxes and sediment trap data are not to be overrated. However, apparent trapping efficiencies $\geq 100 \%$ occur for 15 of the 21 deep trap measurements, i.e., model particle fluxes are on average lower than trap measurements.

Generally, deep traps are deployed at significant depth above the seafloor in order to prevent resuspension effects, but in most areas under discussion the seafloor topography is so rugged that resuspension from mountain ridges or continental slopes is conceivable. In some cases, it is known that lateral inputs occur. In particular, the deeper King George Basin (site KG, Bransfield Strait) seems to act as a natural sediment trap with particles originating from the nearby shelf and slope sediments (Abelmann and Gersonde, 1991). Consequently, biogenic opal could be supplied to the deeper trap in a larger proportion compared to POC due to a lower remineralization in the surface sediments. At site CV, model derived POC fluxes are low whereas biogenic opal fluxes are high relative to the flux data (Fig. 6). This might be caused by lateral advection of organic rich particles (e.g., from flagellates) to the sampling site from the outer Cape Ghir filament located far to the east of the study site (Neuer et al., 1997). The lower opal fluxes collected by the trap compared to the model are difficult to explain, but may be attributed to either dissolution of opal in the cups (due to very low contents) or an undersampling of smaller diatoms followed by disintegration of diatom-containing fecal pellets at greater depths, or both.

Summarizing the results, the model particle fluxes at shallow depths are on average higher than fluxes measured in sediment traps, whereas at the deep traps, model particle fluxes tend to be lower than measurements.

It has been suggested that radionuclides can be used to calibrate sediment traps (Deuser et al., 1981; Buesseler, 1991; Murnane et al., 1996). Scholten et al. (2001) found that ${ }^{230} \mathrm{Th}$ fluxes indicate low trapping efficiencies in shallow traps (at the average $40 \%$ ). In 
deep traps, they found larger as well as lower particle fluxes than calculated from ${ }^{230} \mathrm{Th}$ budgets. Recently, Yu et al. (2001) published new data of radionuclide calibrations of sediment traps. They documented undertrapping of traps deployed in the mesopelagic zone (shallower than $1500 \mathrm{~m}$ ), whereas the deep traps appear to bear no systematic undertrapping resp. overtrapping. Thus, some of the model data misfits may be explained by missing normalization using radionuclides.

For a more detailed comparison, we included literature values of ${ }^{230} \mathrm{Th}$-derived trapping efficiencies available for some of the traps in Table 7 .

For all shallow traps, the ${ }^{230}$ Th-derived trapping efficiency is in agreement with our results insofar that they all indicate undertrapping. At the deep traps, our model results indicate over-as well as undertrapping, which is also the case for the ${ }^{230} \mathrm{Th}$-estimations. In particular, the fact that the only trap that is clearly undertrapping as estimated from ${ }^{230}$ Th-budgets, CV1/ 2 , is also one of the rare traps, which bears an 'apparent trapping efficiency' smaller than unity supports the validity of our approach.

It has to be noted that the ${ }^{230}$ Th-trapping efficiency is calculated as the measured ${ }^{230} \mathrm{Th}$ flux divided by the expected ${ }^{230}$ Th flux by mass. It has been hypothesized that ${ }^{230} \mathrm{Th}$ is particle selective in its scavenging behaviour with respect to particle composition as well as particle size (Thomson et al., 1993; Luo and $\mathrm{Ku}$, 1999; Luo et al., 2001; Geibert and Usbeck, submitted). It is thus not surprising that the ${ }^{230} \mathrm{Th}$-trapping efficiency differs in its exact numbers from our 'apparent trapping efficiencies' calculated from nutrient budgets for POC and opal separately.

In conclusion, the results from this study using the AAMOCC model confirm that uncorrected sediment trap data from shallow depths underestimate vertical particle fluxes of carbon and opal and the overall effectiveness of the biological pump. The general agreement of the model results with radionuclide studies gives additional support for the use of ${ }^{230} \mathrm{Th}$ corrections to estimate the trapping efficiency for a specific deployment even in uncertainties remain. The very large range in observation to model flux ratios is moreover an indication of high variability of particle fluxes in time and space. Long time series of ${ }^{230} \mathrm{Th}$-corrected fluxes at a large number of stations are required to derive reliable flux values for global budgets.

\section{Acknowledgements}

Comments by W. Geibert and M. Rutgers van der Loeff during the preparation of this manuscript were very helpful. We also like to thank Ken O. Buesseler for critically reading the manuscript and providing valuable comments to improve this manuscript.

\section{References}

Abelmann, A., Gersonde, R., 1991. Biosiliceous particle flux in the Southern Ocean. Marine Chemistry 35, 503-536.

Antia, A.N., Maaßen, J., Herman, P., Voß, M., Scholten, J., Groom, S., Miller, P., 2001. Spatial and temporal variability of particle flux at the N.W. European continental margin. Deep Sea Research 48 (2), 3083-3106.

Antoine, D., Morel, A., 1996. Oceanic primary production: 1. Adaption of a spectral light-photosynthesis model in view of application to satellite chlorophyll observations. Global Biogeochemical Cycles 10, 43-55.

Antoine, D., André, J.M., Morel, A., 1996. Oceanic primary production: 2. Estimation at global scale (coastal zone color scanner) chlorophyll. Global Biogeochemical Cycles 10, 57-69.

Bacon, M.P., Huh, C.A., Fleer, A.P., Deuser, W.G., 1985. Seasonality in the flux of natural radionuclides and plutonium in the deep Sargasso Sea. Deep Sea Research 32, 273-286.

Baker, E.T., Milburn, H., Tennant, D.A., 1988. Field assessment of sediment trap efficiency under varying flow conditions. Journal of Marine Research 46 (3), 573-592.

BATS, 1998. Bermuda Atlantic Time-Series Study. Internet: http:// www.bbsr.edu/cintoo/bats/bats.html.

Berger, W.H., Wefer, G., 1990. Export production: seasonality and intermittency, and paleoceanographic implications. Paleogeography, Paleoclimatology, Paleoecology 89, 245-254.

Berger., W.H., Fischer, K., Lai, C., Wu, G., 1987. Ocean productivity and organic carbon flux: Part I. Overview and maps of primary production and export production. Tech. Rep. Reference Series 87-30, SIO, Scripps Institution of Oceanography, University of California.

Bishop, J.K.B., 1989. Regional extremes in particulate matter composition and flux: effects on the chemistry of the ocean interior. In: Berger, W.H., Smetacek, V.S., Wefer, G. (Eds.), Productivity of the Ocean: Present and Past. No. 44 in Dahlem Workshop Reports. Wiley, Chichester, pp. 117-137.

Buesseler, K.O., 1991. Do upper-ocean sediment traps provide an accurate record of particle flux? Nature 353, 420-423.

Buesseler, K.O., 1998. The decoupling of production and particulate export in the surface ocean. Global Biogeochemical Cycles 12, 297-310.

Buesseler, K.O., Bacon, M.P., Cochran, J.K., Livingston, H.D., 1992. Carbon and nitrogen export during the JGOFS North Atlantic Bloom Experiment estimated from ${ }^{234} \mathrm{Th}:{ }^{238} \mathrm{U}$ disequilibria. Deep Sea Research 39 (7-8a), 1115-1137.

Buesseler, K.O., Michaels, A.F., Siegel, D.A., Knap, A.H., 1994. A 
three dimensional time-dependent approach to calibrating sediment trap fluxes. Global Biogeochemical Cycles 8, 179-193.

de las Heras, M., Schlitzer, R., 1999. On the importance of intermediate water flows for the global ocean overturning. Journal of Geophysical Research 104, 15515-15536.

Deuser, W.G., Ross, E.H., Anderson, R.F., 1981. Seasonality in the supply of sediment to the deep Sargasso Sea and implications for the rapid transfer of matter to the deep ocean. Deep Sea Research 28A, 495-505.

Eppley, R.W., Peterson, B.J., 1979. Particulate organic matter flux and planktonic new production in the deep ocean. Nature 282, 677-680.

Fischer, G., Wefer, G., 1996. Long-term observation of particle fluxes in the Eastern Atlantic: seasonality, changes of flux with depth and comparison with the sediment record. In: Wefer, G., Berger, W.H., Siedler, G., Webb, D.J. (Eds.), The South Atlantic: Present and Past Circulation. Springer, Heidelberg, pp. $325-344$.

Fischer, G., Fütterer, D., Gersonde, R., Honjo, S., Ostermann, D., Wefer, G., 1988. Seasonal variability of particle flux in the Weddell Sea and its relation to ice cover. Nature 335, 426-428.

Fischer, G., Donner, B., Ratmeyer, V., Davenport, R., Wefer, G., 1996a. Distinct year-to-year particle flux variations off Cape Blanc during 1988-1991: relation to $\delta^{18} \mathrm{O}$-deduced sea-surface temperatures and trade winds. Journal of Marine Research 54, $73-98$.

Fischer, G., Neuer, S., Wefer, G., 1996b. Short-term sedimentation pulses recorded with a fluorescence sensor and sediment traps at 900-m depth in the Canary basin. Limnology and Oceanography 41 (6), 1354-1359.

Fischer, G., Ratmeyer, V., Wefer, G., 2000. Organic carbon fluxes in the Atlantic and the Southern Ocean: relationship to primary production compiled from satellite radiometer data. Deep Sea Research 47, $1961-1997$.

Geibert, W., Usbeck, R., 2002. The adsorption of Thorium and Protactinium on different particle types in dependence of the provenance of natural seawater. Geochimica et Cosmochimica Acta (submitted).

Gust, G., Michaels, A.F., Johnson, A., Deuser, W.G., Bowles, W., 1994. Mooring line motions and sediment trap hydrodynamics: in situ intercomparison of three common deployment designs. Deep Sea Research 41, 831-857.

Heinze, C., Maier-Reimer, E., Winguth, A.M.E., Archer, D., 1999. A global oceanic sediment model for long term climate studies. Global Biogeochemical Cycles 13 (1), 221-250.

Henderson, G.M., Heinze, C., Anderson, R.F., Winguth, A.M.E., 1999. Global distribution of the ${ }^{230} \mathrm{Th}$ flux to ocean sediments constrained by GCM modelling. Deep Sea Research 46 (I), $1861-1893$.

Honjo, S., Manganini, S.J., 1993. Annual biogenic particle fluxes to the interior of the North Atlantic Ocean; studied $34^{\circ} \mathrm{N} 21^{\circ} \mathrm{W}$ and $48^{\circ} \mathrm{N} 21^{\circ} \mathrm{W}$. Deep Sea Research 40, 587-607.

Honjo, S., Manganini, S.J., 1996. Annual biogenic particle fluxes to the interior of the North Atlantic Ocean; studied at $34^{\circ} \mathrm{N} 21^{\circ} \mathrm{W}$ and $48^{\circ} \mathrm{N} 21^{\circ} \mathrm{W}$. In: Milliman, J.D. (Ed.), Topical Studies in Oceanography, JGOFS: The North Atlantic Bloom Experiment. Pergamon, Oxford, pp. 587-607.
Joos, F., Plattner, G.K., Stocker, T.F., Marchal, O., Schmittner, A., 1999. Global warming and marine carbon cycle feedbacks on future atmospheric $\mathrm{CO}_{2}$. Nature 284, 464-467.

Luo, S., Ku, T.-L., 1999. Oceanic ${ }^{231} \mathrm{~Pa}^{230} \mathrm{Th}$ ratio influenced by particle composition and remineralization. Earth and Planetary Science Letters 167, 183-195.

Luo, S., Ku, T.-L., Wang, L., Southon, J.R., Lund, S.P., Schwartz, M., 2001. ${ }^{26} \mathrm{Al},{ }^{10} \mathrm{Be}$ and $\mathrm{U}-\mathrm{Th}$ isotopes in Blake Outer Ridge sediments: implications for past changes in boundary scavenging. Earth and Planetary Science Letters 185, 135-147.

Maier-Reimer, E., 1993. Geochemical cycles in an ocean general circulation model. Preindustrial tracer distributions. Global Biogeochemical Cycles 7, 645-677.

Martin, J.H., Knauer, G.A., Karl, D.M., Broenkow, W.W., 1987. VERTEX: carbon cycling in the northeast Pacific. Deep Sea Research 34, 267-286.

Michaels, A.F., Bates, N.R., Buesseler, K.O., Carlson, C.A., Knap, A.H., 1997. Carbo-cycle imbalances in the Sargasso Sea. Nature $372,537-540$.

Murnane, R.J., Cochran, J.K., Buessler, K.O., Bacon, M.P., 1996. Least-squares estimates of thorium, particle, and nutrient cycling rate constants from the JGOFS North Atlantic Bloom Experiment. Deep Sea Research 43, 239-258.

NABE, 1998. JGOFS: North Atlantic Bloom Experiment. Internet: http://www1.whoi.edu/nabe.html.

Najjar, R.G., Sarmiento, J.L., Toggweiler, J.R., 1992. Downward transport and fate of organic matter in the ocean: simulations with a general circulation model. Global Biogeochemical Cycles $6,45-76$.

Neuer, S., Ratmeyer, V., Davenport, R., Fischer, G., Wefer, G., 1997. Deep water particle flux in the canary island region: seasonal trends in relation to long-term satellite derived pigment data and lateral sources. Deep Sea Research 44, 1451-1466.

Pondaven, P., Ragueneau, O., Tréguer, P., Hauvespre, A., Dezileau, L., Reyss, J.L., 2000. Resolving the 'opal paradox' in the Southern Ocean. Nature 405, 168-169.

Ragueneau, O., Tréguer, P., Leynaert, A., Anderson, R.F., Brzezinski, M.A., DeMaster, D.J., Dugdale, R.C., Dymond, J., Fischer, G., Francois, R., Heinze, C., Maier-Reimer, E., Martin-Jézéquel, V., Nelson, D.M., Quéguiner, B., 2000. A review of the Si cycle in the modern ocean: recent progress and missing gaps in the application of biogenic opal as paleoproductivity proxy. Global and Planetary Change 4, 317-365.

Schlitzer, R., 1993. Determining the mean, large-scale circulation of the Atlantic with the adjoint method. Journal of Physical Oceanography 23, 1935-1952.

Schlitzer, R., 1995. An adjoint method for the determination of the mean oceanic circulation, air-sea fluxes and mixing coefficients. Reports on Polar Research 156, AWI, Bremerhaven.

Schlitzer, R., 1996. Mass and heat transports in the South Atlantic derived from historical data. In: Wefer, G., Berger, W.H., Siedler, G., Webb, D.J. (Eds.), The South Atlantic. Springer, Berlin, pp. 305-323.

Schlitzer, R., 2000. Applying the adjoint method for global biogeochemical modeling. In: Kasibhatla, P., Heimann, M., Hartley, D., Mahowald, N., Prinn, R., Rayner, P. (Eds.), Inverse Methods in Biogeochemical Cycles. AGU, USA, pp. 107-124. 
Scholten, J.C., Fietzke, J., Rutgers van der Loeff, M.M., Mangini, A., Koeve, W., Stoffers, P., Antia, A., Neuer, S., Waniek, J., 2001. Trapping efficiencies of sediment traps from the deep eastern North Atlantic: the ${ }^{230}$ Th calibration. Deep Sea Research 48, 2383-2408.

SeaWiFS, 1998. SeaWIFS. Internet: http://seawifs.gsfc.nasa.gov/ SEAWIFS.html.

Siegel, D.A., Deuser, W.G., 1997. Trajectories of sinking particles in the Sargasso Sea: modeling of statistical funnels above deep-ocean sediment traps. Deep Sea Research 44 (9-10), $1519-1541$.

Suess, E., 1980. Particulate organic carbon flux in the ocean-surface productivity and oxygen utilization. Nature 280, 260-263.

Thacker, W.C., 1988. Fitting models to inadequate data by enforcing spatial and temporal smoothness. Journal of Geophysical Research 93, 655-664.

Thomson, J., Colley, S., Anderson, R., Cook, G.T., MacKenzie, A.B., Harkness, D.D., 1993. Holocene sediment fluxes in the Northeast Atlantic from ${ }^{230} \mathrm{Th}$ excess and radiocarbon measurements. Paleoceanography 8 (5), 631-650.

Usbeck, R., 1999. Modeling of marine biogeochemical cycles with an emphasis on vertical particle fluxes. Reports on Polar Research 332, AWI, Bremerhaven, http://www.awi-bremerhaven.de/GEO/ Publ/PhDs/RUsbeck.

Vogler, S., Scholten, J., Rutgers van der Loeff, M., Mangini, A., 1998. ${ }^{230} \mathrm{Th}$ in the Eastern North atlantic: the importance of water mass ventilation in the balance of ${ }^{230} \mathrm{Th}$. Earth and Planetary Science Letters 156 (1-2), 61-74.

Volk, T., Hoffert, M.I., 1985. Ocean carbon pumps: analysis of relative strengths and efficiencies in ocean-driven atmospheric $\mathrm{CO}_{2}$ changes. In: Sundquist, E., Broecker, W.S. (Eds.), The Carbon Cycle and Atmospheric $\mathrm{CO}_{2}$ : Natural Variations Archean to Present. No. 32 in Geophysical Monograph. AGU, Washington, DC, pp. 99-110.

Walsh, I., Dymond, J., Collier, R., 1988. Rates of recycling of biogenic components of settling particles in the ocean derived from sediment trap experiments. Deep Sea Research 35, $43-58$.

Walter, H.J., 1998. Scavenging of ${ }^{231} \mathrm{~Pa}$ and ${ }^{230} \mathrm{Th}$ in the South Atlantic implications for the use of the ${ }^{231} \mathrm{~Pa}^{230} \mathrm{Th}$ ration as a paleoproductivity proxy. Reports on Polar Research, vol. 282. AWI, Bremerhaven.

Walter, H.J., Geibert, W., Rutgers vander Loef, M.M., Fischer, G., Bathmann, U.V., 2001. Shallow vs. deep-water scavenging of ${ }^{231} \mathrm{~Pa}$ and ${ }^{230} \mathrm{Th}$ in radionuclide enriched waters of the Atlantic sector of the Southern Ocean. Deep Sea Research 48 (1), $471-493$.

Wassmann, P., 1993. Regulation of vertical export of particulate organic matter from the euphotic zone by planktonic heterotrophs in eutrophicated aquatic environments. Marine Pollution Bulletin 26, 636-643.

Wassmann, P., Slagstad, D., 1993. Seasonal and annual dynamics of particulate organic carbon flux in the Barents Sea. Polar Biology $13,363-372$.

Wefer, G., Fischer, G., 1991. Annual primary production and export flux in the Southern Ocean from sediment trap data. Marine Chemistry 35, 597-613.

Yamanaka, Y., Tajika, E., 1996. The role of the vertical fluxes of particulate organic matter and calcite in the oceanic carbon cycle: studies using an ocean biogeochemical general circulation model. Global Biogeochemical Cycles 10, 361-382.

Yamanaka, Y., Tajika, E., 1997. Role of dissolved organic matter in the marine biogeochemical cycle: studies using an ocean biogeochemical general circulation model. Global Biogeochemical Cycles 11, 599-612.

Yu, E.F., Francois, R., Bacon, M.P., Honjo, S., Manganini, S.J., Rutgers van der Loeff, M.M., Ittekot, V., 2001. Trapping efficiency of bottom-tethered sediment traps estimated from the intercepted fluxes of ${ }^{230} \mathrm{Th}$ and ${ }^{231} \mathrm{~Pa}$. Deep Sea Research 48, $865-889$. 